\title{
Athletes sleep duration during COVID-19 pandemic and its relationship with health condition
}

\author{
Jull Kurniarobbi, Chikih Chikih, Muhammad Andeansah, Ria Lestari, Irfan Sukendar \\ Department of Community Medicine, Faculty of Medicine, Universitas Indonesia, Jakarta, Indonesia
}

\begin{tabular}{l} 
Article Info \\
\hline Article history: \\
Received 26 Jun, 2021 \\
Revised Nov 2, 2021 \\
Accepted Nov 16, 2021 \\
\hline
\end{tabular}

\section{Keywords:}

Adolescent athlete

Health monitoring

Sleep duration

Sports epidemiology

\begin{abstract}
During the coronavirus desease 2019 (COVID-19) pandemic, athletes must be able to adapt to new habits, such as: social restriction, change of competition schedule, and sending back home. This situation has led to an $18.2 \%$ increase in sleep disturbances. This study aimed to look at the sleep duration of adolescent athletes during the COVID-19 pandemic and its impact on athlete's health conditions. A total of 126 adolescent athletes from 15 sports were recruited in this cross-sectional study. Adequate sleep duration was assessed according to the American Academy of Sleep Medicine criteria. Data on health conditions, medical history, injury history, were taken using a questionnaire. Behavioral assessment was assessed through the strengths and difficulties questionnaire. About $80.2 \%$ of adolescent athletes had insufficient sleep, and there was a significant relationship between sleep duration and disease incidence with a relative risk (RR) of $3.31(1.32-8.28) 95 \%$ convidence interval (CI). There was no significant relationship between adequate sleep duration and health conditions ( $p>0.05)$. Things that may be the cause of sleep disturbances; use of electronic devices $(37.6 \%)$, environmental conditions $(53.4 \%)$, and worry (9\%). In the end, this indicates adolescent athletes face difficulties in achieving adequate sleep duration during this pandemic and a continuous surveillance system is needed to monitor athletes outside the dormitory.
\end{abstract}

This is an open access article under the CC BY-SA license.

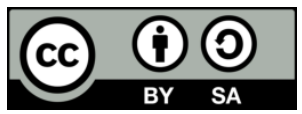

\section{Corresponding Author:}

Chikih Chikih

Department of Community Medicine, Faculty of Medicine, Universitas Indonesia

Jakarta Pusat, DKI Jakarta, Indonesia

Email: chikih.md.dma@gmail.com

\section{INTRODUCTION}

Sleep is a very important physiological function to create optimal health [1], [2]. According to the American Academy of Sleep Medicine (AASM), adults are recommended to sleep between seven and nine hours per day to obtain optimal health and performance, while adolescents aged 13-18 years are recommended to have more sleep time, which is eight to ten hours per day [1]-[3]. Adequate sleep time depends on the components of quality, quantity, characteristics, and habits of a person and it is applied to an athlete too [4], [5]. Sleep is greatly beneficial in improving sports performance, because it is related to the recovery time that allows cellular adaptation, thereby reducing the risk of health problems, psychological disorders, impaired cognitive function, and minimizing the risk of injury [2], [4]. The sleep deviation is believed to be one of the causes for lost sports performance and increased injury risk in an athlete [2], [4]. In this pandemic situation, people try to adapt to social activities restrictions, work schedules adjustment, and the loss of business opportunities. This condition led to an increase of anxiety disorders $35.1 \%$, depressive symptoms $20.1 \%$, and sleep disturbances by $18.2 \%$ [6], [7]. This sleep disturbance can also affect athlete and its increases the awareness of athlete recovery [8]. The problem of inadequate sleep duration in athletes is 
suspected to increase in the coronavirus disease 2019 (COVID-19) pandemic situation [7]. Pandemic conditions also forced athletes to adapt, especially in the adolescent athlete population. Adolescent athletes who undergo training must be sent home so that they are free from the supervision of training loads, health conditions, and disciplinary rules. Thus, this research aimed: i) to find out the description of adolescent athletes' sleep duration during the COVID-19 pandemic lockdown, ii) to find out the description of the health condition of adolescent athletes during the COVID-19 pandemic lockdown, iii) to find out the determinant factors that can affect sleep duration among adolescent athletes, and iv) to find out the relationship between adequate sleep duration and health conditions in adolescent athletes during the lockdown.

\section{RESEARCH METHOD}

\subsection{Study design and sampling method}

This research was conducted with a cross-sectional study design. The population of this study was adolescent athletes from sports schools in Jakarta. They were male and female adolescent athletes aged 13-18 from 15 different sports, with secondary and high school academic activities. They stay and doing sports training in the boarding facilities provided in the same location. During the COVID-19 pandemic, all school and sports activities were stopped and all athletes were returned to their homes. While in their home areas, all athletes continue to train regularly and supervision is only carried out online within an uncertain period.

The calculation of the sample size was carried out using the formula of binomial proportion, with $\mathrm{Z} \alpha=5 \%$ and a power level of $95 \%$. The injuries proportion calculation in athletes using the research results of Rosen et al. [9]. The minimum number needed for these research subjects is 90. In this research 203 respondents were participated. In this research, the respondent was taken by purposive sampling. The inclusion criterias were: i) athletes are active in sports schools, ii) adolescent athletes who want to participate and have parental consent, and the exclusion criteria, iii) adolescent athletes who did not fill out all research questionnaires completely. In this study, the age group was categorized into the age group of 13-15 years and 16-18 years according to the level of education undertaken by the adolescent athletes at school (secondary and high school).

\subsection{Variables and instruments}

All data were collected through questionnaires which were distributed and completed online. There are two questionnaires for this research; the first questionnaire was used for subject identities and profile data. Subject identities and profiles consist of name, age, gender, type of sport, weight, height, hours of sleep, hours of wakeup, and possible sleep disturbances (using electronic devices, environmental conditions, and feelings of worry). Second a questionnaire about the incidence of illness, injury, and behavioral difficulties strengths and difficulties questionnaire (SDQ). Researchers also grouped sports into contact sports, limited contact, and non-contact. However, we combined limited contact sports with contact sports. Contact sports consist of basketball, volleyball, wrestling, pencak silat, football, taekwondo, and non-contact sports consist of weightlifting, athletics, badminton, diving, archery, swimming, gymnastics, tennis, and table tennis [10].

The incidence of illness and injuries data were obtained based on the presence or absence of symptoms and signs of illness and injury experienced during training at home, while data on behavioral difficulties were obtained based on the SDQ questionnaire. Health conditions refer to the WHO definition [11]; Health is a state of complete physical, mental and social well-being and not merely the absence of disease or infirmity. Subjects are declared to have a good health condition if they do not experience symptoms and signs of illness, injury, or behavioral difficulties. Sleep adequacy was assessed based on the cumulative hours from the time that the subject is sleeping until the time that the subject is waking up. And according to the consensus of the American Academy of Sleep Medicine, sleep adequacy is divided into the category of adequate sleep with a duration of 8 or more and the category of insufficient sleep if the length of sleep is less than 8 hours, for ages 13-18 years [12], [13]. Body mass index was calculated and classified into less, normal, and obese categories, based on the criteria of the Ministry of Health of the Republic of Indonesia [14]. Assessment of behavioral difficulties was using the strengths and difficulties questionnaire (SDQ) published by the Directorate of Family Education Development, Ministry of Education and Culture of the Republic of Indonesia which has been validated [15]. The total SDQ score is categorized as normal conditions with a score of $0-15$, border conditions with a score of 16-19, and abnormal conditions score 2040. Abnormal conditions are considered to represent behavioral difficulties; therefore, a further approach is needed for the subjects to explore and overcome problems that the subject may face during the COVID-19 pandemic. 


\subsection{Data analysis}

Data analysis was carried out with the help of SPSS series 18 software (IBM, University of Indonesia) and it was performed to obtain an overview and relationship according to the research objectives. Descriptive statistics were conducted to describe the characteristics of the research subjects. The collected data were analyzed using Chi-square or Fisher's test according to statistical requirements. The confounding factors role such as age, gender, body mass index, and sport was analyzed by logistic regression test. This research is part of the main research that has passed the ethical review from the Medical Research Ethics Committee FKUI-RSCM (KET-696/UN2.F1/ETIK/PPM.00.02/2020).

\section{RESULTS AND DISCUSSION}

\subsection{Subject characteristics}

From the population of 203 adolescent athletes, 77 (37\%) subjects were dropout because did not complete the research questionnaire, so only 126 subject's data were obtained and analyzed. The characteristics of the research subjects are described in Table 1.

Table 1. Descriptive subject characteristics

\begin{tabular}{lcc}
\hline \multicolumn{1}{c}{ Variable } & $\mathrm{n}$ & Percentage (\%) \\
\hline Age & 17 & 13.5 \\
Group 13-15 years & 109 & 86.5 \\
Group 16-18 years & & \\
Gender & 65 & 51.6 \\
Male & 61 & 48.4 \\
Female & & \\
Body mass index & 105 & 83.3 \\
Normal & 21 & 16.7 \\
Abnormal & & \\
Sports & 53 & 42.1 \\
Contact & 73 & 57.9 \\
Non-contact \\
Behavioral difficulties (SDQ) & & \\
Normal & 117 & 92.9 \\
Abnormal & 9 & 7.1 \\
Sleep duration & & \\
Insufficient sleep & 101 & 80.2 \\
Adequate sleep & 25 & 19.8 \\
Possible sleep disturbances & & \\
Electronic devices & 38 & 37.6 \\
Environmental conditions & 54 & 53.4 \\
Feelings of worry & 9 & 9 \\
Health condition & & \\
Ailing & 112 & 89.6 \\
Healthy & 14 & 19.8 \\
Incidence of injury & & \\
Injury & 83 & 65.2 \\
No injury & & 34.8 \\
Incidence of illness & 43 & 73 \\
Illness & & 27 \\
No illness & 92 & \\
\hline
\end{tabular}

In this study, the result indicated that $80.2 \%$ of athletes were having insufficient sleep during the pandemic. The results of this study are different from Facer-Childs et al. [16]. The results of Facer-Childs's study described a longer duration of sleep during the pandemic compared with this study. Facer-Childs et al. state athlete's sleep duration during the lockdown period was increased by $0.6-0.8$ hours, but athletes also reported an increase in daytime sleepiness $(\mathrm{p}=0.01)$ compared before the pandemic. This happened because the athletes sleep and woke up behind their regular schedule before the pandemic. These changes lead to poor sleep quality, which has implications for the occurrence of depression, stress, and reduced sun exposure in athletes. Change bedtime schedule in Facer-Childs et al. study is caused by the consumption of alcohol, caffeine, screen time before bed, electronic screen light, and room light. The difference from Facer-Childs's study is due to the difference in the questionnaire used in collecting the data.

In this study researcher found that 101 athletes who have insufficient sleep, $38(37.6 \%)$ athletes were found to play electronic devices before going to bed, 54 (53.4\%) people felt that the environment was not the same as in the dormitory, and 9 (9\%) felt worried. This result is per research from Kölling et al. [17], which explains that the possibility of sleeping difficulties can be caused by changes in competition or match schedules, use of electronic devices, travel, and nocturnal dreaming. 
This study also found that $89.6 \%$ of adolescent athletes have ailing health conditions, it was assessed based on WHO definition, with description $73 \%$ of athletes were having an illness, $62.5 \%$ of athletes suffered injuries, and $7.1 \%$ of athletes had behavioral difficulties (SDQ) in pandemic lockdown. Victorian injury surveillance unit (VISU) from Monash University release data about sports injury rates during pandemic [18]. The percentage for unintentional sports injuries was slightly higher in pandemic than in the 2017-2019 comparison periods (17\% vs. 15\%, respectively). With an increase in the location of the incident at home, non-specific sports venues, specific sports activity, and athletic venues. In this study, researchers do not have data on the incidence of injury, illness, and behavioral difficulties (SDQ) before the pandemic, so we cannot make comparison data before and after the pandemic.

\subsection{Adequate sleep duration and health conditions}

The relationship between adequate sleep time and health conditions was not statistically significant $\mathrm{p}=0.475$ as shown in Table 2. This was different from the study by Kim et al. [19] which stated that insufficient sleep duration increased the risk of unhealthy health perceptions by 1.358 (95\% convidence interval (CI) 1.091-1.601) compared to with adequate sleep duration. Future more this result was also contrasting from the study of Stefan et al. [20] It stated that insufficient sleep duration increased the risk of ailing health condition assessment by 0.43 (95\% CI 0.26-0.69) compared to normal sleep duration. The difference in the results because health conditions in Kim et al. [19] and Stefan et al. [20] were assessed based on perceptions or self-assessment of their body conditions before the pandemic, while in this study health conditions were assessed based on WHO definition, which are: i) the occurrence of one or simultaneously of the following conditions, ii) illness, injury, and behavioral difficulties. However, this study found that proportion of the subjects with insufficient sleep have more ailing health conditions compare with adequate sleep $91 / 112(81.25 \%)$ vs. $21 / 112(18.75 \%)$. This result becomes important for us to show that sleep duration is one of the predictors of the occurrence of health conditions disorder for athletes, and this is per research from Frange et al. [21] which conclude that the issue of sleep duration should be considered when describing health conditions, cause sleep duration can lead to adverse outcomes in global health status.

Table 2. The relationship between sleep time and health conditions

\begin{tabular}{ccccc}
\hline & \multicolumn{2}{c}{$\begin{array}{c}\text { Health } \\
\text { conditions } \\
\end{array}$} & $\begin{array}{c}\text { Percentage } \\
(\%)\end{array}$ & p-value \\
& Ailing & Healthy & & \\
\hline Insufficient sleep & 91 & 10 & 80.2 & $>0.05^{*}$ \\
Adequate sleep & 21 & 4 & 19.8 & \\
Total & 112 & 14 & 100 & \\
*Fisher test & & & &
\end{tabular}

\subsection{The relationship of adequate sleep time with injury and illness}

The relationship between adequate sleep time and the incidence of injury was not statistically significant relative risk (RR) 0.902 (95\% CI 0.361-2.252; $\mathrm{p}=0.825)$ are described in Table 3 . The results of this study are in line with a systematic review study from Clemente et al. [22], which found inconsistency from several studies showing that lack of sleep in soccer has a negative impact on athletic performance, match performance, and severity of musculoskeletal injuries. However, Clemente et al. seem to suggest that insufficient sleep affects soccer player performance and increases the risk of injury and need to this complex relationship further. A systematic review from Dobrosielski et al. [23], also said that there is insufficient evidence supporting the association between subjective or objective measures of sleep and injury in collegiate and elite athletes. When applied to this current finding, the researcher may consider examining the role of sleep as a moderating variable for incidence of injury, and must be able to exclude other confounding factors: sleep quality, sport, and training load. The dynamic model of etiology in sports injury said, predisposition factor for athlete become injury divide into two categories, which is extrinsic and intrinsic factor and this is also explained in the study of Prieto-González et al. [24] and Moseid et al. [25], which state that $59.28 \%$ injuries occurred during a training session and higher injuries rate associated with: i) greater number of hours of practice per week, ii) not performing warm-ups, iii) using inadequate sports facilities, iv) being aged 14-17, v) not performing physical preparation, vi) inappropriate training load, vii) not performing injury-preventive activities, viii) performing sports techniques without the supervision of one sports coach, and ix) inadequate sports equipment [24], [25]. But in this study researcher did not search for the cause of the injury while the athlete was outside the dormitory, due to the limitations of the data collection method used.

This study found a significant relationship between adequate sleep duration and illness in adolescent athletes as shown in Table 4, with RR 3.31 (95\% CI 1.32-8.28; p=0.008). The result is consistent and corroborates with the studies conducted by Prather et al. [26], [27], and Wentz et al. [28]. The three studies 
have shown that insufficient sleep duration increased the risk of developing the flu 2.57 (95\% CI 1.10-6.02), increased the risk of upper respiratory tract infection by 4.4 (95\% CI 1.5-12.9), and increased the risk of the common cold by 4.24 (95\% CI 1.08-16.71). This consistent study results show had lack of sleep increased the risk of illness, regardless of differences in the sleep duration assessment instruments and sleep determination criteria used.

Table 3. The relationship between sleep time and injury

\begin{tabular}{lcccc}
\hline & \multicolumn{3}{c}{ Incidence of injury } \\
& Injury & No injury & $\begin{array}{c}\text { Percentage } \\
(\%)\end{array}$ & p-value \\
\hline Insufficient sleep & 67 & 34 & 80.2 & $>0.05^{*}$ \\
Adequate sleep & 16 & 9 & 19.8 & \\
Total & 83 & 43 & 100 & \\
$*$ Chi-square test & & & &
\end{tabular}

*Chi-square test

This occurs because chronic deficiency of sleep duration (short sleep duration or sleep disturbances) increases the systemic inflammatory response, which can cause inflammation. This inflammation can decrease the immune system, especially against infectious diseases [29]. The formation of the immune system occurs during sleep, and sleep affects the activation and adaptation of our body's defense system to fight infection [29]. So, it is very important to optimize sleep quality and quantity in athletes including approaches to extend total sleep duration, improve the sleep environment, and identify potential sleep disorders for an athlete [30].

Table 4. Relationship between sleep time and illness

\begin{tabular}{lcccc}
\hline & \multicolumn{2}{c}{ Incidence of illness } & $\begin{array}{c}\text { Percentage } \\
(\%)\end{array}$ & p-value \\
& Illness & No illness & $(\%)$ & $<0.05^{*}$ \\
\hline Insufficient sleep & 79 & 22 & 80,2 & \\
Adequate sleep & 13 & 12 & 19,8 & \\
Total & 92 & 34 & 100 & \\
*Fisher test & & &
\end{tabular}

\subsection{Relationship of individual characteristics with health conditions}

The relationship between the characteristics of athletes (age, gender, sport, body mass index, and behavioral difficulties (SDQ) with health conditions during pandemic lockdown) was carried out with logistic regression (Table 5). The result shows that characteristics of the subject do not affect the health condition.

Table 5. Binary logistic regression

\begin{tabular}{lcccc}
\hline & \multicolumn{4}{c}{ Health Conditions } \\
& B & Sig. & Exp(B) & CI 95\% for $\operatorname{Exp}(\mathrm{B})$ \\
\hline Age & 0.56 & 0.667 & 1.676 & $0.159-17.627$ \\
Gender & 18.808 & 0.997 & 1473 & - \\
Body mass index & 0.56 & 0.667 & 1.676 & $0.159-17.627$ \\
Sports & -0.62 & 0.949 & 0.94 & $0.140-6.314$ \\
Behavioral difficulties & 40.301 & 0.998 & 0.000 & - \\
\hline
\end{tabular}

In this cross-sectional investigation, the data were collected during the pandemic period and have been conducted for six months. Recall bias could not be controlled and it is a limitation for this study. The $37 \%$ dropout rate occurs due to difficulties in telemonitoring during the COVID-19 pandemic.

\section{CONCLUSION}

The results of the research, show that adolescent athletes during the COVID-19 pandemic face difficulty in achieving adequate sleep. The proportion of adolescent athletes who have ailing health conditions are greater than adolescent athletes who have sufficient sleep. Currently, no system can monitor the condition of athletes when outside the dormitory. To sum up, this study shows that adequate sleep is something that should receive more attention, especially related to the incident of illness, with the aim that adolescent athletes can maintain their health during the COVID-19 pandemic. In this study, researchers highlighted sleep duration, the incidence of injury, the incidence of illness, and behavioral difficulties in athletes, while outside the dormitory because of pandemic situations. This opens up new research opportunities, regarding the need for a monitoring system for athlete conditions outside the dormitory. This monitoring system must be able to monitor physical and psychological conditions as well as the training load carried out by athletes. 


\section{ACKNOWLEDGEMENTS}

Thank to the head of the Center of Sports Exercise Study, Indonesian Medical Education and Research Institute Faculty of Medicine Universitas Indonesia (IMERI-FKUI) Dr. dr. Nani Cahyani, Sp.KO, who has provided the opportunity to conduct joint major research on adolescent athletes during the COVID-19 pandemic.

\section{REFERENCES}

[1] A. M. Watson, "Sleep and athletic performance," Current Sports Medicine Reports, vol. 16, no. 6, pp. 413-418, 2017, doi: 10.1249/JSR.0000000000000418.

[2] J. Charest and M. A. Grandner, "Sleep and athletic performance: Impacts on physical performance, mental performance, injury risk and recovery, and mental health," Sleep Medicine Clinics, vol. 15, no. 1, pp. 41-57, 2020, doi: 10.1016/j.jsmc.2019.11.005.

[3] S. Dwivedi, A. Boduch, B. Gao, M. D. Milewski, and A. I. Cruz, "Sleep and injury in the young athlete," JBJS Reviews, vol. 7, no. 9, pp. 1-8, 2019, doi: 10.2106/JBJS.RVW.18.00197.

[4] A. Bender, H. Van Dongen, and C. Samuels, "Sleep quality and chronotype differences between elite athletes and non-athlete controls," Clocks \& Sleep, vol. 1, no. 1, pp. 3-12, 2018, doi: 10.3390/clockssleep1010002.

[5] C. D. Mah, E. J. Kezirian, B. M. Marcello, and W. C. Dement, "Poor sleep quality and insufficient sleep of a collegiate studentathlete population," Sleep Health, vol. 4, no. 3, pp. 251-257, 2018, doi: 10.1016/j.sleh.2018.02.005.

[6] Y. Huang and N. Zhao, "Generalized anxiety disorder, depressive symptoms and sleep quality during COVID-19 outbreak in China: a web-based cross-sectional survey," Psychiatry Research, vol. 288, no. April, p. 112954, 2020, A doi: 10.1016/j.psychres.2020.112954.

[7] H. Xiao, Y. Zhang, D. Kong, S. Li, and N. Yang, "Social capital and sleep quality in individuals who self-isolated for 14 days during the coronavirus disease 2019 (COVID-19) outbreak in January 2020 in China," Medical Science Monitor, vol. 26, pp. 1-8, 2020, doi: 10.12659/MSM.923921

[8] K. Khalladi et al., "Inter-relationship between sleep quality, insomnia and sleep disorders in professional soccer players," $B M J$ Open Sport and Exercise Medicine, vol. 5, no. 1, pp. 1-7, 2019, doi: 10.1136/bmjsem-2018-000498.

[9] P. Von Rosen, A. Kottorp, C. Fridén, A. Frohm, and A. Heijne, "Young, talented and injured: Injury perceptions, experiences and consequences in adolescent elite athletes," European Journal of Sport Science, vol. 18, no. 5, pp. 731-740, 2018, doi: 10.1080/17461391.2018.1440009.

[10] S. G. Rice et al., "Medical conditions affecting sports participation," Pediatrics, vol. 121, no. 4, pp. 841-848, 2008, doi: 10.1542/peds.2008-0080.

[11] WHO, "Preamble to the Constitution of WHO as adopted by the International Health Conference, New York," Official Records of WHO. p. 100, 1948, [Online]. Available: https://www.who.int/governance/eb/who_constitution_en.pdf (accessed Jan. 26, 2021).

[12] S. Paruthi et al., "Consensus Statement of the American Academy of Sleep Medicine on the Recommended Amount of Sleep for Healthy Children: Methodology and Discussion,” Journal of Clinical Sleep Medicine, vol. 12, no. 11, pp. 1549-1561, 2016, doi: $10.5664 /$ jcsm.6288.

[13] J. P. Chaput, C. Dutil, and H. Sampasa-Kanyinga, "Sleeping hours: What is the ideal number and how does age impact this?," Nature and Science of Sleep, vol. 10, pp. 421-430, 2018, doi: 10.2147/NSS.S163071.

[14] Ministry of Health Republic of Indonesia, "Obesity epidemic,"Jurnal Kesehatan. Directorate General of Disease Prevention and Control, Ministry of Health - Republic of Indonesia, Jakarta, pp. 1-8, 2018, [Online] Available: http://p2ptm.kemkes.go.id/dokumen-ptm/factsheet-obesitas-kit-informasi-obesitas (accessed Jan. 26, 2021)

[15] S. Wimbarti, J. Siregar, M. Oktaviana, and R. Regiastri, "Strengths and difficulties questionnaire parent report (sdq-pr) as screening instrument of children mental health in Indonesia," Jurnal Psikologi vol. 46, no. 2, pp. 130-144, 2019, doi: 10.22146/jpsi.46698.

[16] E. R. Facer-Childs, D. Hoffman, J. N. Tran, S. P. A. Drummond, and S. M. W. Rajaratnam, "Sleep and mental health in athletes during COVID-19 lockdown," Sleep, vol. 44, no. 5, pp. 1-9, 2021, doi: 10.1093/sleep/zsaa261.

[17] S. Kölling, R. Duffield, D. Erlacher, R. Venter, and S. L. Halson, "Sleep-related issues for recovery and performance in athletes," International Journal of Sports Physiology and Performance, vol. 14, no. 2, pp. 144-148, 2019, doi: 10.1123/ijspp.2017-0746.

[18] Monash University, "Injuries during the COVID-19," vol. 1, no. August. Monash University Accident Research Centre (MUARC), p. 36, 2021. [Online]. Available: https://www.monash.edu/muarc/research/research-areas/home-andcommunity/visu/injuries-during-the-covid-19-pandemic (accessed March 26, 2021).

[19] J. Kim, K. R. Kim, D. Ph, K. H. Cho, K. Yoo, and J. A. Kwon, "The association between sleep duration and self-rated health," vol. 9, no. 10, 2013, doi: $10.5664 \% 2$ Fjesm.3082.

[20] L. Štefan, D. Juranko, R. Prosoli, R. Barić, and G. Sporiš, "Self-reported sleep duration and self-rated health in young adults," Journal of Clinical Sleep Medicine, vol. 13, no. 7, pp. 899-904, 2017, doi: 10.5664/jcsm.6662.

[21] C. Frange, S. S. de Queiroz, J. M. da Silva Prado, S. Tufik, and M. T. de Mello, "The impact of sleep duration on self-rated health," Sleep Science, vol. 7, no. 2, pp. 107-113, 2014, doi: 10.1016/j.slsci.2014.09.006.

[22] F. M. Clemente, J. Afonso, J. Costa, R. Oliveira, J. Pino-Ortega, and M. Rico-González, "Relationships between sleep, athletic and match performance, training load, and injuries: A systematic review of soccer players," Healthcare (Switzerland), vol. 9, no. 7, 2021, doi: 10.3390/healthcare9070808.

[23] D. A. Dobrosielski, L. Sweeney, and P. J. Lisman, "The association between poor sleep and the incidence of sport and physical training-related injuries in adult athletic populations: A systematic review," Sports Medicine, vol. 51, no. 4, pp. 777-793, 2021, doi: $10.1007 / \mathrm{s} 40279-020-01416-3$.

[24] P. Prieto-González, J. L. Martínez-Castillo, L. M. Fernández-Galván, A. Casado, S. Soporki, and J. Sánchez-Infante, "Epidemiology of sports-related injuries and associated risk factors in adolescent athletes: An injury surveillance," International Journal of Environmental Research and Public Health, vol. 18, no. 9, 2021, doi: 10.3390/ijerph18094857.

[25] C. H. Moseid, G. Myklebust, M. W. Fagerland, B. Clarsen, and R. Bahr, "The prevalence and severity of health problems in youth elite sports: A 6-month prospective cohort study of 320 athletes," Scandinavian Journal of Medicine \& Science in Sports, vol. 28, no. 4, pp. 1412-1423, Apr. 2018, doi: 10.1111/sms.13047.

[26] A. A. Prather, D. Janicki-Deverts, N. E. Adler, M. Hall, and S. Cohen, "Sleep habits and susceptibility to upper respiratory illness: the moderating role of subjective socioeconomic status," Annals of Behavioral Medicine, vol. 51, no. 1, pp. 137-146, 2017, doi: $10.1007 / \mathrm{s} 12160-016-9835-3$. 
[27] A. A. Prather, D. Janicki-Deverts, M. H. Hall, and S. Cohen, "Behaviorally assessed sleep and susceptibility to the common cold," Sleep, vol. 38, no. 9, pp. 1353-1359, 2015, doi: 10.5665/sleep.4968.

[28] L. M. Wentz et al., "Increased risk of upper respiratory infection in military recruits who report sleeping less than 6 h per night," Military Medicine, vol. 183, no. 11-12, pp. E699--E704, 2018, doi: 10.1093/milmed/usy090.

[29] L. Besedovsky, T. Lange, and M. Haack, "The sleep-immune crosstalk in health and disease," Physiological Reviews, vol. 99, no. 3, pp. 1325-1380, 2019, doi: 10.1152/physrev.00010.2018.

[30] N. S. Simpson, E. L. Gibbs, and G. O. Matheson, "Optimizing sleep to maximize performance: implications and recommendations for elite athletes," Scandinavian Journal of Medicine and Science in Sports, vol. 27, no. 3, pp. 266-274, 2017, doi: $10.1111 / \mathrm{sms} .12703$.

\section{BIOGRAPHIES OF AUTHORS}
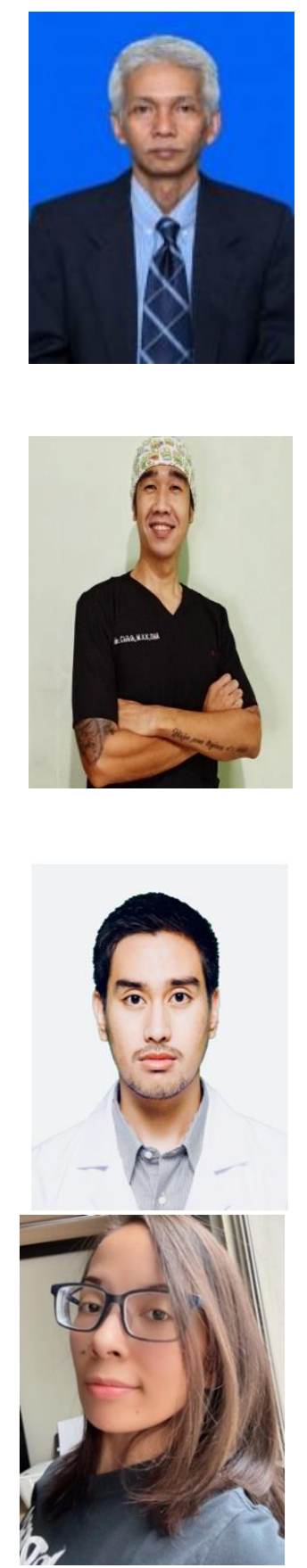

Jull Kurniarobbi (iD SI SC P is a medical specialist in Sports Medicine working as lecturer at Sports Medicine Training Program, Faculty of Medicine Universitas Indonesia. He is also working at National Sports Hospital, a special hospital safeguarding health and wellbeing of elite athlete, student athlete and recreational athlete. His main interest covers risk factors contributed to injury and illness among sports and exercise participants or enthusiasts. During Covid-19 pandemic his interest inclines toward the relation between sports and exercise activity with susceptibility, transmission and severity of Covid-19, as well as the impact of pandemic situation to sports and exercise participants. He can be contacted at email: jull.kurniarobbi@ui.ac.id.

Chikih Chikih (D) $8 \mathrm{SC}$ is a hyperbaric and diving medicine doctor and certified in Science of Training Young Athletes from the University of Florida. Currently, he is in a residency program in Sports Medicine Study Program, Faculty of Medicine, University of Indonesia. $\mathrm{He}$ is interested in hyperbaric oxygen therapy for sports recovery, sports science and development for young athlete. He can be contacted at email: chikih.md.dma@ gmail.com or chikih01@ui.ac.id.

Muhammad Andeansah (iD 8 SC P is a Sports Medicine Resident at Universitas Indonesia in Jakarta and a certified clinical exercise physiologist in Indonesia. He has an interest in the field of exercise as medicine. He was a Research Assistant in Dr. Hassan Sadikin Central General Hospital, Bandung, Indonesia. He can be contacted at email: mandeansah@gmail.com.

Ria Lestari (iD 8D SC P is a Sports Medicine Resident at Universitas Indonesia in Jakarta. She is interested in female athletes and sports injuries. She was a Research Assistant in Heidelberg Repatriation Hospital, Melbourne, Australia. Currently, she is writing her thesis about low energy availability in female dancer. She can be contacted at email: rukawa.ria@gmail.com. 


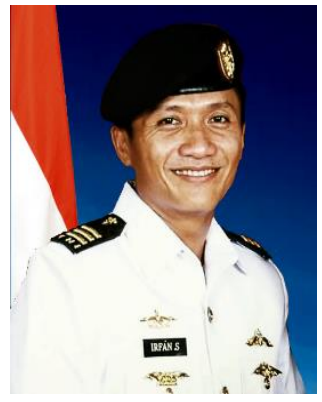

Irfan Sukendar (iD 8. SC P is an Indonesian Navy Military Doctor. Currently, he is in a residency program in Sports Medicine Study Program, Faculty of Medicine, University of Indonesia. He has an interest in being able to research and develop knowledge regarding the prevention of overuse injuries and physiological adaptation in military personnel. He can be contacted at email: irfan.sukendar@gmail.com. 